\title{
Brazilian Journal of Chemical

\section{OXIDATION OF ZINC SULPHIDE CONCENTRATE IN A FLUIDISED BED REACTOR - PART 2: THE INFLUENCE OF EXPERIMENTAL VARIABLES ON THE KINETICS}

\author{
C. A. R. Queiroz*, R. J. Carvalho and F. J. Moura \\ Departamento de Ciência dos Materiais e Metalurgia, Pontifícia Universidade Católica \\ do Rio de Janeiro, Phone: +(55) (021) 3114-1563, Fax: +(55)(021) 3114-1236, Rua Marquês \\ de São Vicente 225, CEP 22453-900, Gávea, Rio de Janeiro - RJ, Brazil. \\ E-mail: rjcar@dcmm.puc-rio.br.
}

(Received: February 27, 2004 ; Accepted: August18, 2004)

\begin{abstract}
The oxidation kinetics of a blend of zinc sulphide concentrates in a bench-scale fluidised bed reactor operated in batch regime was studied. The fractional conversion was determined by measuring the $\mathrm{SO}_{2}$ concentration in the exit gas using a chromatograph. The effects of the initial mass of the blend, airflow rate and temperature on fractional conversion were studied. The initial mass of the blend varied from 45 to $75 \mathrm{~g}$, the airflow rate from 6 to $9 \mathrm{~L} / \mathrm{min}$ and the temperature from 883 to $1213 \mathrm{~K}$. The time for complete conversion was affected by the molar ratio of $\mathrm{O}_{2}$ to $\mathrm{S}$ fed into the reactor and by temperature. The oxidation reaction was controlled by surface chemical reaction of the unreacted core of the particles. The value of the activation energy, $87 \mathrm{~kJ} / \mathrm{mole}$, supports the contention that the reaction was chemically controlled.

Keywords: Zinc sulphide oxidation; Fluidised bed; Kinetics.
\end{abstract}

\section{INTRODUCTION}

The process of zinc production from sulphide ores involves a pyrometallurgical operation, oxidising roasting, followed by leaching of the oxide formed and subsequent extraction of zinc by electrolysis. The roasting of the zinc sulphide concentrate with air can be done in a fluidised bed reactor, operated continuously for high productivity.

Some experimental studies have been conducted with the purpose of studying the kinetics of the oxidation reaction of zinc sulphide (Fukunaka et al., 1976; Natesan and Philbrook, 1970; Gray et al., 1974). These studies used pellets or particles in fluidised beds. The raw materials used were synthetic agglomerates, pretreated concentrates and natural concentrates. It was shown that the removal of sulphur is affected by temperature and oxygen partial pressure and that the rate-controlling step of the reaction is the diffusion of $\mathrm{O}_{2}$ through the layer of zinc oxide formed and/or reaction on the surface of the unreacted core of zinc sulphide.

The reaction below, representing the oxidation of zinc sulphide, is exothermic and can be considered irreversible.

$\mathrm{ZnS}(\mathrm{s})+3 / 2 \mathrm{O}_{2}(\mathrm{~g})=\mathrm{ZnO}(\mathrm{s})+\mathrm{SO}_{2}(\mathrm{~g})$

$\Delta \mathrm{H}=-450 \mathrm{~kJ} / \mathrm{mole} \mathrm{ZnS}\left(600-1000{ }^{0} \mathrm{C}\right)$

*To whom correspondence should be addressed 
It is well known that for natural concentrates, reactivity, porosity, morphology and impurities can affect the reaction rate.

In this work, the kinetics of the oxidising roasting reaction of an industrial blend of zinc sulphide concentrates with air was studied using a batch fluidised bed reactor on a bench scale. The fluid dynamics characterisation of the system has already been presented (Queiroz et al.). The minimum fluidisation velocity determined using a cold model, and the experimental conditions were established with fluid dynamics maps and an analysis of the dynamics of gas bubble growth.

\section{EXPERIMENTAL}

\section{Materials}

The blend of zinc sulphide concentrates used in this work came from Salavery, Peru. This material was $-42+100$ mesh $(162$ to $324 \mu \mathrm{m})$. Table 1 shows its chemical composition.

Pure nitrogen gas and air supplied by a compressor were used in the experiments after having been dried.

\section{Experimental Procedure}

The fluidised bed apparatus shown in Figure 1 consisted of a stainless steel tube (AISI 316) with an external diameter of $48 \mathrm{~mm}$, an internal diameter of $45 \mathrm{~mm}$ and a length of $700 \mathrm{~mm}$. A highly porous aluminium oxide plate was used as gas distributor and was placed at the midsection of the reactor. An electric furnace, controlled by a temperature controller coupled with a thermocouple, heated the reactor externally. Due to exothermic reactions, an annulus $200 \mathrm{~mm}$ in length and $60 \mathrm{~mm}$ in diameter was used to cool the system with air. A U manometer connected at two orifices, one close to the porous plate and the other above the bed, measured the gas pressure drop in the bed. The actual bed temperature was measured by a thermocouple immersed in the expanded bed. A sampling tube was connected at the exit of the reactor.

Weighed amounts of the concentrate blend were fed into the preheated reactor, while a flow of nitrogen was passed through the bed to provide an inert atmosphere. When the reactor reached the desired temperature, the nitrogen flow was discontinued and a calibrated flow of air passed through the gas distributor.

A mass balance of sulphur determined the fractional conversion of the concentrate blend before and after the reaction, measuring the $\mathrm{SO}_{2}$ concentration in the exit gas with a chromatograph. During the reaction, gas samples were taken from the gas-sampling tube at regular time intervals using a syringe. The remaining gases were treated in a column containing hydrogen peroxide in order to absorb the $\mathrm{SO}_{2}$ before release into the atmosphere.

The effects of initial mass of the concentrate blend, airflow rate and temperature on fractional conversion were studied. The initial mass of the concentrate blend varied from 45 to $75 \mathrm{~g}$, the airflow rate from 6 to $9 \mathrm{~L} / \mathrm{min}$ and the temperature from 883 to $1213 \mathrm{~K}$.

Table 1: Chemical analysis of the blend of zinc sulphide concentrates

\begin{tabular}{|c|c|c|c|c|c|}
\hline Component & wt pet & Component & wt pct & Component & ppm \\
\hline $\mathbf{Z n}$ & 56.18 & $\mathrm{Cd}$ & 0.45 & $\mathrm{Ni}$ & 10 \\
$\mathbf{F e}$ & 5.02 & $\mathrm{Cu}$ & 0.45 & $\mathrm{Co}$ & 10 \\
$\mathbf{S}$ & 33.2 & $\mathrm{~Pb}$ & 0.81 & $\mathrm{As}$ & 2428 \\
$\mathbf{M n}$ & 0.56 & $\mathrm{MgO}$ & 0.06 & $\mathrm{Sb}$ & 963 \\
$\mathbf{C a O}$ & 0.18 & $\mathrm{SiO}_{2}$ & 0.99 & $\mathrm{Ge}$ & 9 \\
\hline
\end{tabular}




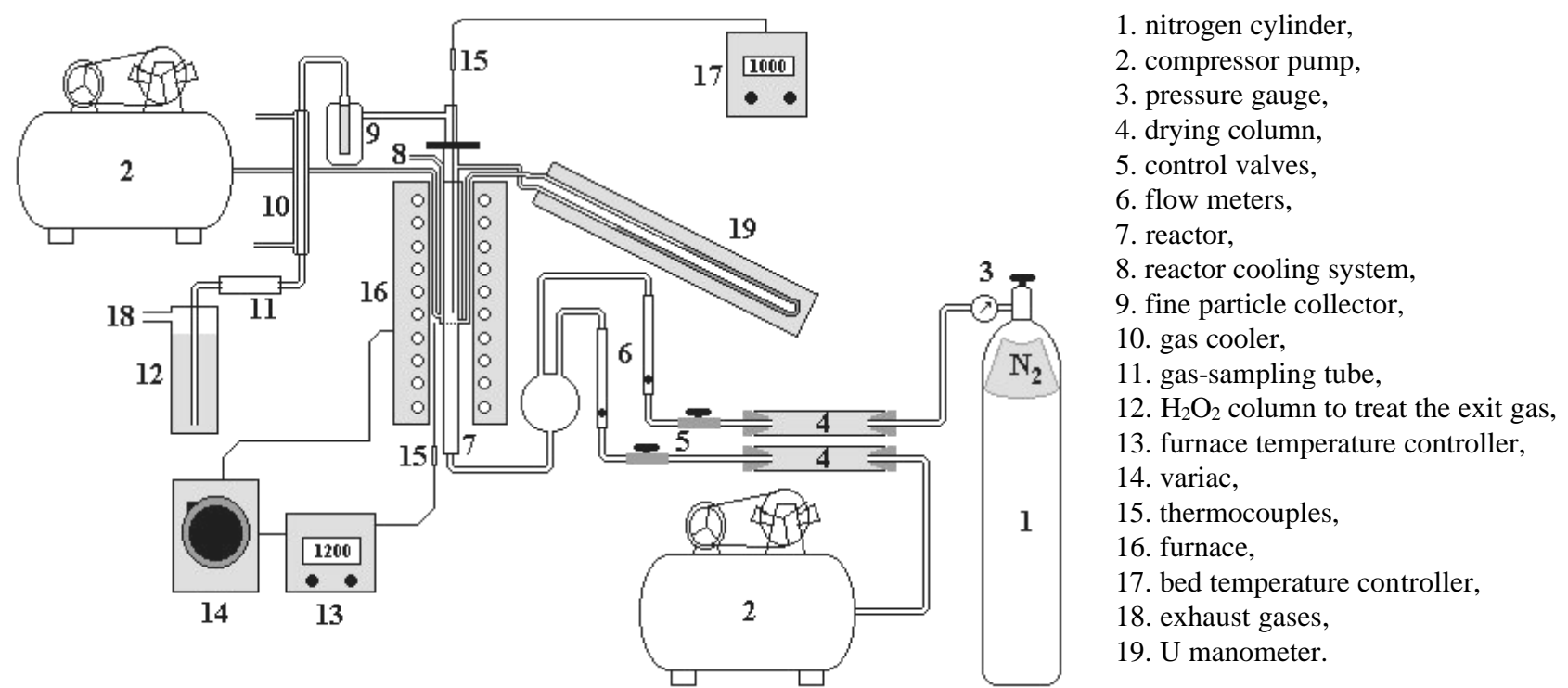

Figure 1: Schematic diagram of the experimental apparatus for the oxidation reaction

\section{RESULTS AND DISCUSSION}

\section{The Effect of Fluidising Gas Flow Rate}

The effect of fluidising gas flow rate on fractional conversion of the concentrate blend was studied at a temperature of $1213 \mathrm{~K}$, an initial blend mass of $45 \mathrm{~g}$ and a mean particle diameter of $162 \mu \mathrm{m}$. Figure 2 shows the effect of airflow on conversion.

As expected, the increase in airflow rate produced an increase in conversion. This increase in conversion is related to an increase in the molar ratio of $\mathrm{O}_{2}$ to $\mathrm{S}$ fed into the bed per unit time. It can also be related to the deleterious influence of mass transfer, which is more effective for low flow rates and decreases progressively as the flow rate increases. However, it is known that when a fluidised bed reactor is operated in the turbulent regime, the effect of mass transfer is not very effective (Kunii and Levenspiel, 1969). The influence of flow rate was evaluated by calculating the amount of $\mathrm{O}_{2}$ fed into and consumed in the reactor per unit time.

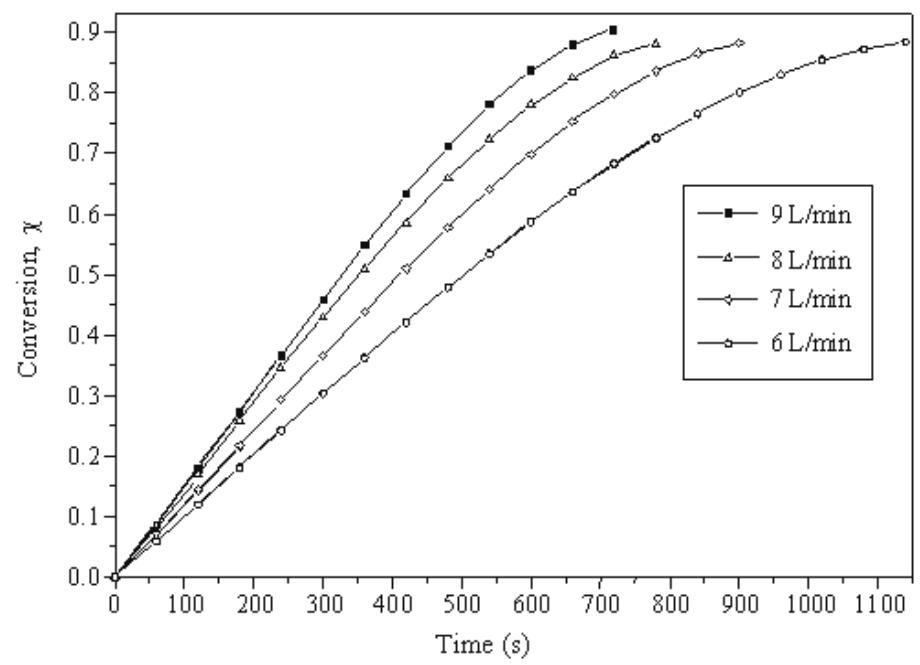

Figure 2: The effect of airflow rate on fractional conversion of the concentrate blend 
Figure 3 shows the ratio of the rate of $\mathrm{O}_{2}$ fed to the rate of that consumed as a function of reaction time. It can be observed in this figure that, for all airflow rates, the $\mathrm{O}_{2}$ feed rate was higher than the $\mathrm{O}_{2}$ consumption rate. It can also be observed that the ratio of the rate of $\mathrm{O}_{2}$ fed to the rate of that consumed is approximately the same for all airflow rates during the first 400 seconds of reaction. This indicates that external mass transfer does not have a significant effect and that the time for complete conversion increases rapidly with the decreasing $\mathrm{O}_{2}$ feed rate.

\section{The Effect of Initial Mass of the Concentrate Blend}

Figure 4 shows the effect of initial mass of the concentrate blend fed into the bed on fractional conversion. The influence of initial mass was addressed for 45,60 and $75 \mathrm{~g}$ of the concentrate blend at a temperature of $1213 \mathrm{~K}$, an airflow rate of 8 $\mathrm{L} / \mathrm{min}$ and a mean particle diameter of $162 \mu \mathrm{m}$.

The influence of initial mass of the concentrate blend is related to the height of the bed and the fluid dynamics characteristics of the fluidised bed reactor. In the heterogeneous fluidisation regime (bubbling), the gas passes through the bed, forming a dense emulsion phase, where most of the solid particles are found, and a diluted phase (bubbles), which is practically without solids (Grace, 1982). In the dense phase the gas flow is homogeneously distributed at a velocity close to the minimum fluidisation velocity.
The remaining gas passes through the bubbles. These bubbles grow mostly by coalescence and rise to the surface of the bed. For small reactors bubble diameter can become as large as the internal diameter of the reactor, resulting in the slugging regime (Kunii and Levenspiel, 1969). The possibility of slugging is more pronounced for deep beds operating with high gas velocities. Slugging of the bed results in a decrease in the gas-solid contact caused by the bypassing of the gas in the form of bubbles, resulting in a low rate of solids conversion.

The possibility of slugging of the bed for the present system has already been studied (Queiroz et al.). For the operational conditions used in this work, the possibility of slugging of the particle bed was determined. In addition, the effect of initial mass of the concentrate blend was evaluated as in the previous section. Figure 5 shows the variation in the ratio of the rate of $\mathrm{O}_{2}$ fed to the rate of that consumed with reaction time for each initial mass used.

Similarly to the runs using different flow rates, the ratio of the rate of $\mathrm{O}_{2}$ fed to the rate of that consumed is approximately the same for all initial masses during the first 400 seconds of reaction. This indicates that the depth of the bed and gas velocity used do not cause slugging of the bed. Therefore, the variation in initial mass does not strongly affect external mass transfer. It can also be observed that there was no lack of oxygen and that reaction time is solely affected by the molar ratio of $\mathrm{O}_{2}$ to $\mathrm{S}$ at the entrance of the reactor.

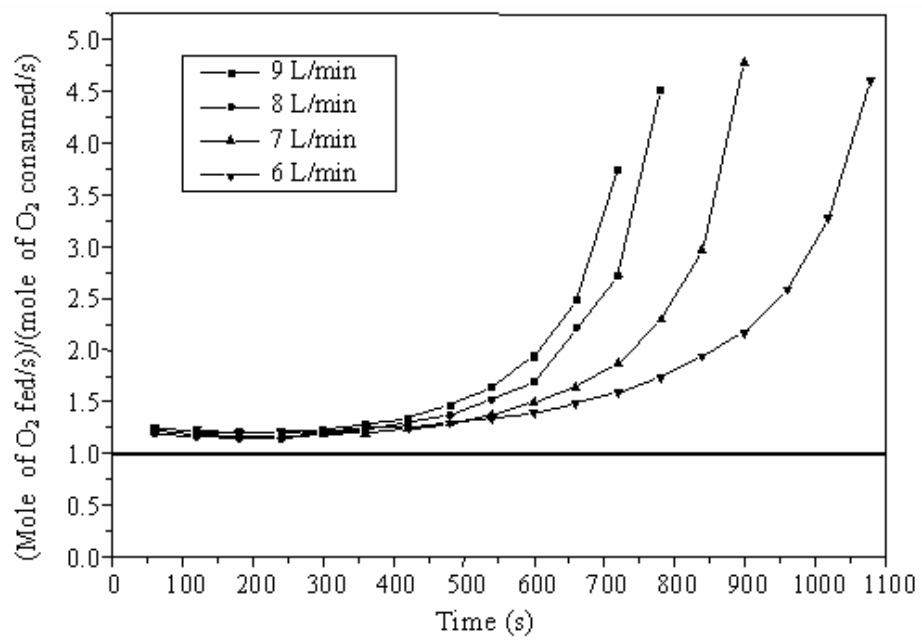

Figure 3: The ratio of the rate of $\mathrm{O}_{2}$ fed to the rate of that consumed as a function of reaction time for different airflow rates 


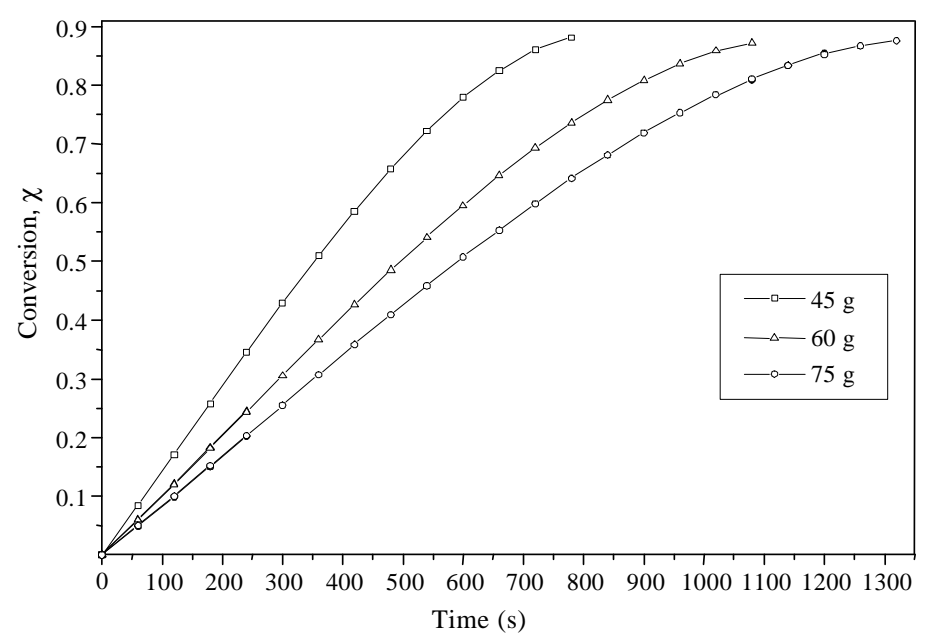

Figure 4: The effect of initial mass of the concentrate blend fed into the bed on fractional conversion

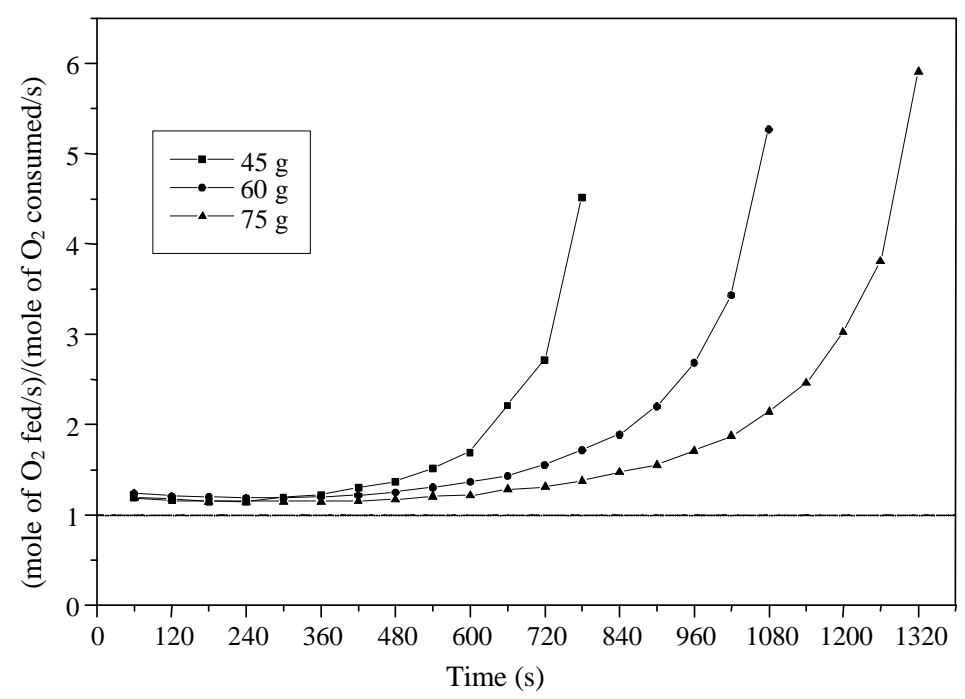

Figure 5: The ratio of the rate of $\mathrm{O}_{2}$ fed to the rate of that consumed as a function of reaction time for each initial mass of the concentrate blend

\section{The Effect of Temperature}

The effect of temperature on fractional conversion of the concentrate blend was studied at 883,1013 , 1113 and $1213 \mathrm{~K}$, an airflow rate of $8 \mathrm{~L} / \mathrm{min}$, an initial mass of concentrate blend of $45 \mathrm{~g}$ and a mean particle diameter of $162 \mu \mathrm{m}$. Figure 6 shows fractional conversion as a function of time.

It can be observed that the conversion rapidly increases with increasing temperature.

With the objective of determining the ratecontrolling mechanism of the reaction, several models were tested. Figure 8 shows the fitting of the experimental results with the shrinking core model (Kunii and Levenspiel, 1969) with chemical reaction control (topochemical model), described by equation 2 .

$$
\frac{\mathrm{t}}{\tau_{\mathrm{cr}}}=1-\left(1-\chi_{\mathrm{ZnS}}\right)^{\frac{1}{3}}
$$

where $\mathrm{t}$ is the reaction time $(\mathrm{s}), \tau_{\mathrm{cr}}$ is the time for complete conversion (s) and $\chi_{\mathrm{ZnS}}$ is the fractional conversion of the concentrate blend (-).

$\tau_{\mathrm{cr}}$ is calculated by equation 3 .

$$
\tau_{\mathrm{cr}}=\frac{\rho_{\mathrm{ZnS}} \quad \mathrm{R}}{\mathrm{b} \quad \mathrm{k}_{\mathrm{r}} \mathrm{C}_{\mathrm{O}_{2} \mathrm{i}}}
$$

where $\rho_{\mathrm{ZnS}}$ is the $\mathrm{ZnS}$ molar density $\left(\mathrm{mole} / \mathrm{cm}^{3}\right), \mathrm{R}$ is the particle radius $(\mathrm{cm}), \mathrm{b}$ is the stoichiometric factor of $2 / 3, \mathrm{k}_{\mathrm{r}}$ is the rate constant of the chemical reaction 
$(\mathrm{cm} / \mathrm{s})$ and $\mathrm{C}_{\mathrm{O} 2 \mathrm{i}}$ is the $\mathrm{O}_{2}$ initial concentration $\left(\mathrm{mole} / \mathrm{cm}^{3}\right)$.

The regression analysis was performed with highly linear correlation coefficients. The results are summarised in Figure 7.

The rate constants $\left(k_{r}\right)$ for the temperature range studied were determined by equations 2 and 3. Figure 8 shows the $\operatorname{lnk}_{\mathrm{r}}$ plotted against the reciprocal of the absolute temperature (Arrhenius plot).

The activation energy, calculated from the
Arrhenius equation, was $87 \mathrm{~kJ} /$ mole. This value is relatively low when compared with the values reported in the literature (Fukunaka et al., 1976; Natesan and Philbrook, 1970). This result is probably due to characteristics of the concentrate blend such as reactivity, porosity and chemical composition. Nevertheless, the magnitude of the dependence of the reaction rate constant on temperature is sufficiently high to suggest that chemical reaction is the controlling step.

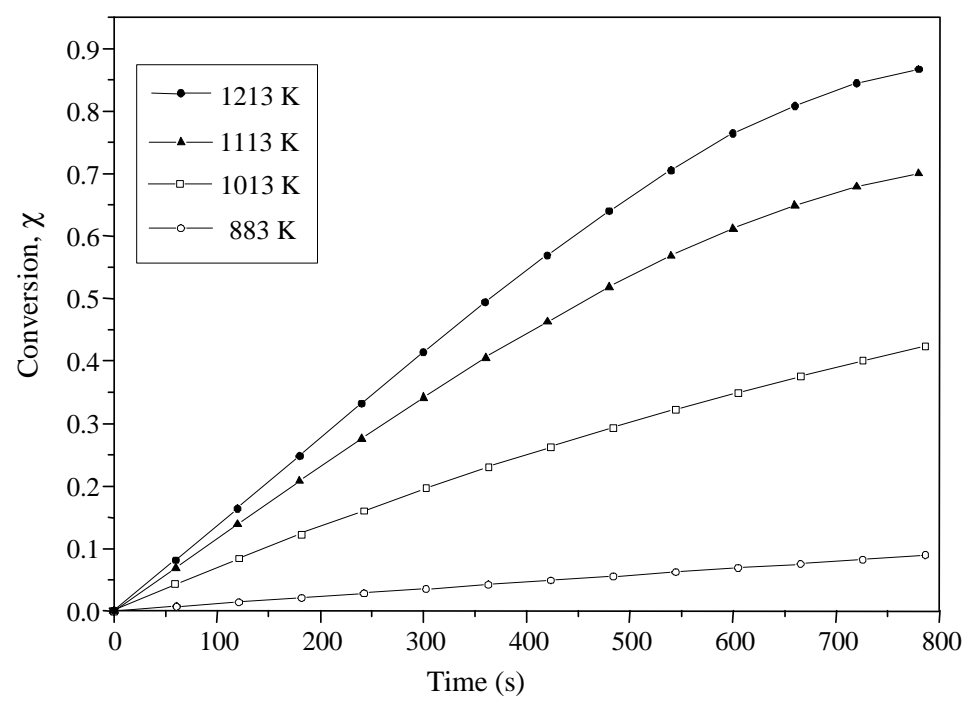

Figure 6: The effect of temperature on fractional conversion of the concentrate blend

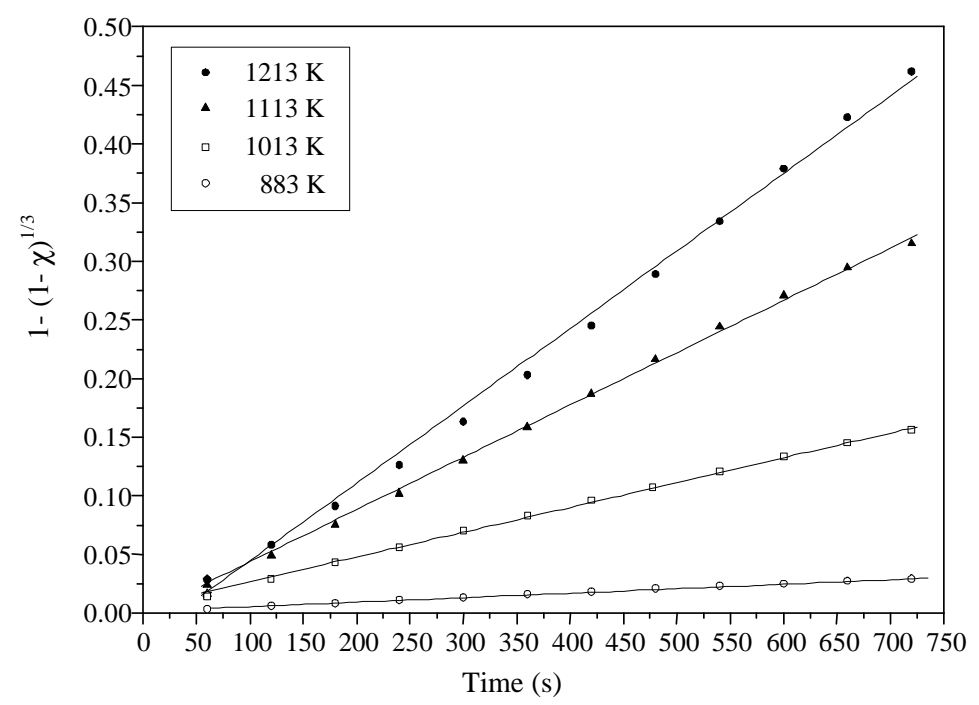

Figure 7: Experimental results and topochemical model fitting 


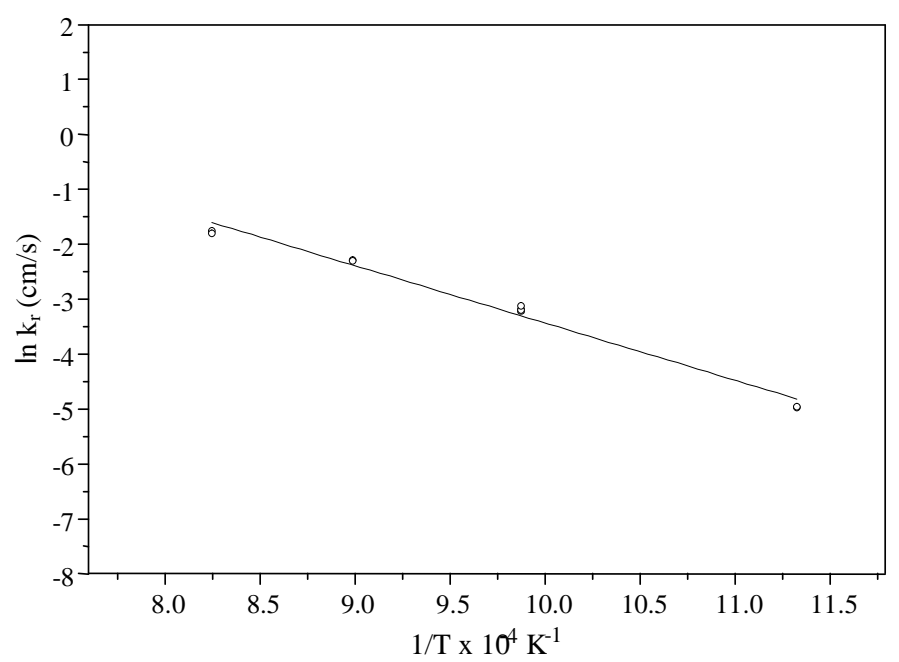

Figure 8: Arrhenius plot $\left(\operatorname{lnk}_{\mathrm{r}}\right.$ versus $\left.1 / \mathrm{T}\right)$

\section{CONCLUSIONS}

The increase in airflow rate to the bed decreased the time for complete conversion of the concentrate blend. The fluidised bed reactor was not affected by slugging, even when deep beds (large initial amounts of concentrate blend) were used. The ratio of the rate of $\mathrm{O}_{2}$ fed to the rate of that consumed is approximately the same for all initial masses during the first 400 seconds of reaction, indicating that the depth of the bed and gas velocity used do not cause slugging of the bed. The results showed that the time for complete conversion of the concentrate blend was affected by the molar ratio of $\mathrm{O}_{2}$ to $\mathrm{S}$ fed into the reactor and by reaction temperature. The activation energy was $87 \mathrm{~kJ} / \mathrm{mole}$, which suggests that chemical reaction on the surface of the unreacted core of the concentrate blend is the controlling step.

\section{ACKNOWLEDGEMENT}

The authors are grateful to the Brazilian government for providing financial support for this research and C. A. R. Queiroz thanks the Brazilian Research Council (CNPq), for the scholarship awarded.

\section{REFERENCES}

Fukunaka, Y., Monta, T., Asaki, Z. and Kondo, Y., Oxidation of Zinc Sulphide in Fluidised Bed, Met. Trans. B., No. 7B, 307 (1976).

Grace, J.R., Fluidised-Bed Hydrodynamics Handbook of Multiphase Systems, Chap. 8, Hetsroni, G., ed., McGraw Hill, New York (1982).

Gray, N.B., Harvey, M.R. and Willis, G.M., Roasting of Sulfides in Theory and Practice Physical Chemistry of Process Metallurgy. The Richardson Conference, J.H.E. Jeffs and R.J. Tait, eds., The Institution of Mining and Metallurgy, London (1974).

Kunii, D. and Levenspiel, O., Fluidisation Engineering, John Wiley \& Sons, New York (1969).

Natesan, K. and Philbrook, W.O., Oxidation Kinetic Studies of Zinc Sulphide in a Fluidised Bed, Met. Trans., No. 1, 1353 (1970).

Queiroz, C.A.R., Carvalho, R.J. and Moura, F.J., Oxidation of Zinc Sulphide Concentrate in a Fluidised Bed Reactor - Part 1: Fluid Dynamic Characterisation of the Particle Bed (in press). 